\title{
Bronchial thermoplasty under conscious sedation in the ambulatory bronchoscopy procedure room
}

I. Ereño Orbea; U. Ortega Mera; O. González Larrocha; B. del Val Villanueva; E. García Perez; S. Telletxea Benguria. Dept. Of Anesthesia. Galdakao-Usansolo Hospital (Basque Country, Spain)

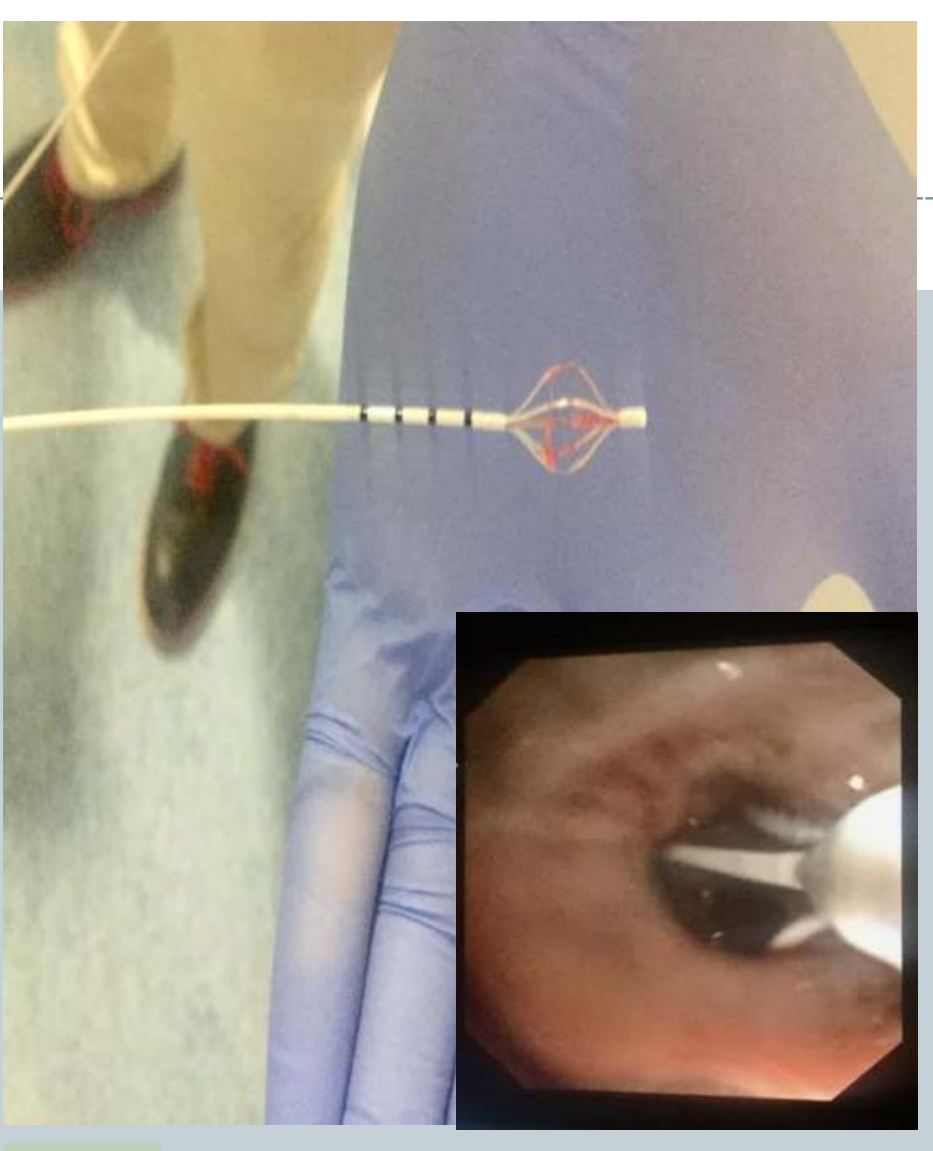

Fig.1

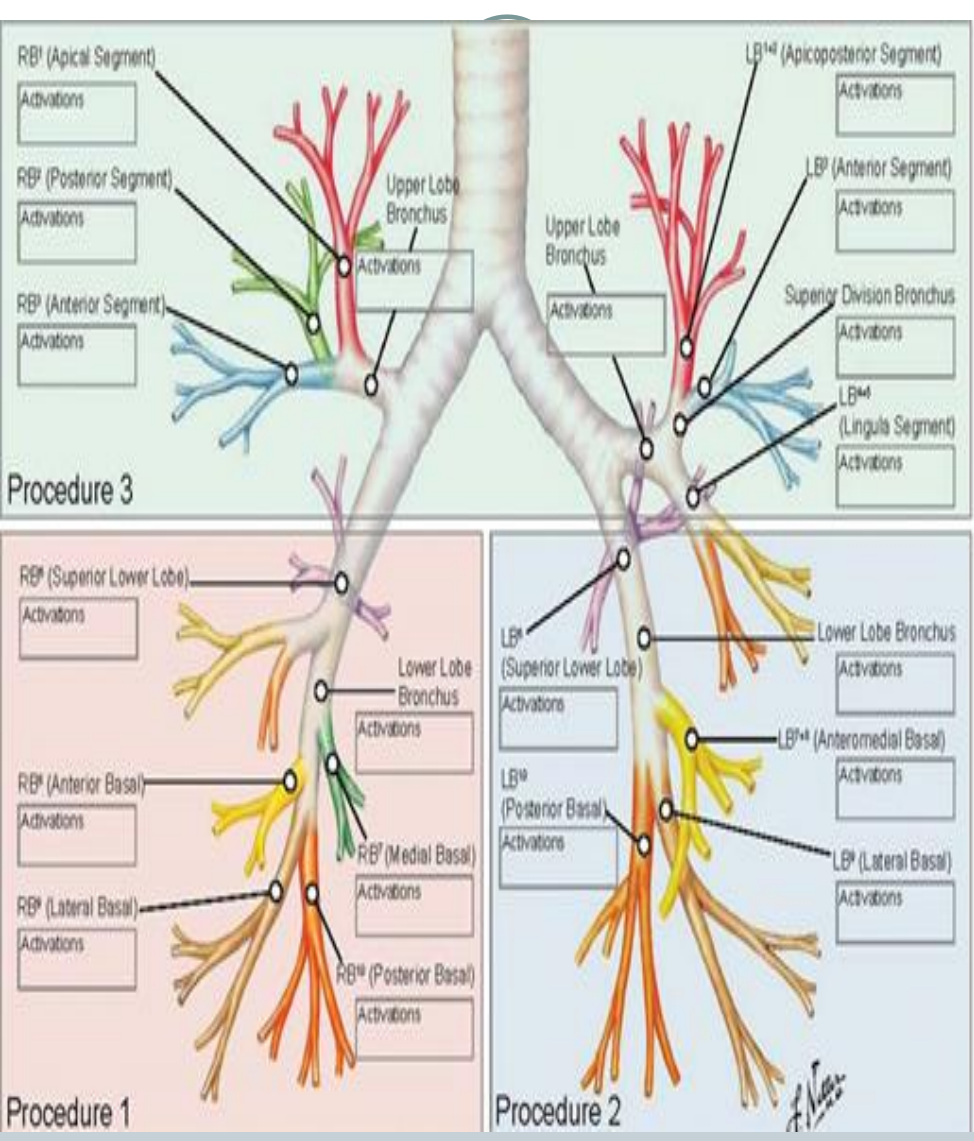

Fig. 2

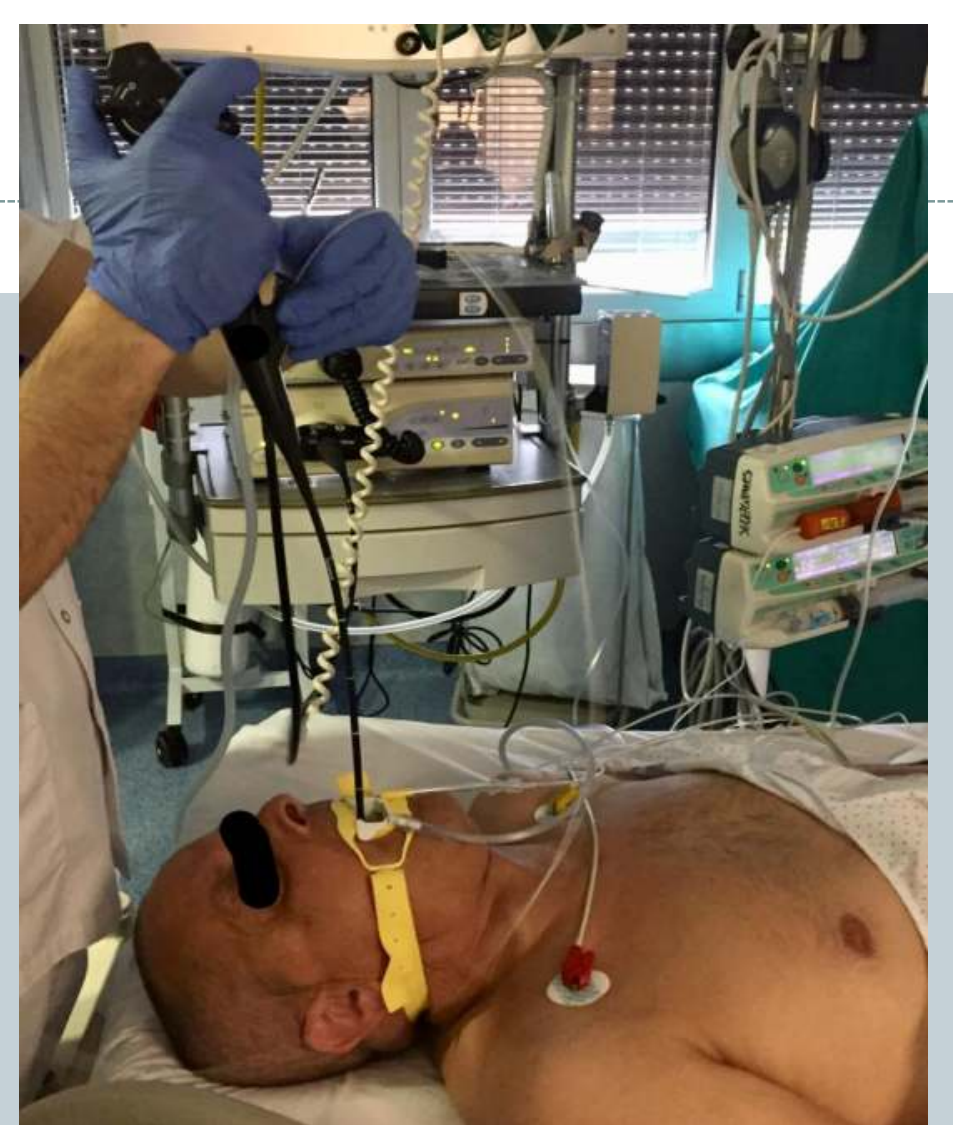

Fig. 3
Bronchial thermoplasty (BT) is an emerging bronchoscopic treatment for refractory asthma. It reduces smooth muscle mass applying radio frequency thermal energy to the airway walls, with a Bronchial Alair TM probe (Fig.1).

It' $s$ divided into 3 sessions, each $45^{\prime}$ long, interspersed with 3 weeks (Fig.2).

The complexity of these patients and the limited literature makes it challenging for the anesthesiologists.

\section{CASE REPORT}

A 59-year old man with severe asthma and serious functional limitation.

After verifying stable disease ${ }^{3}$ and with standard monitoring and peripheral cannulation in the bronchoscopy room:

\section{- Periprocedure Preparation}

-Corticosteroids: $50 \mathrm{mg} /$ day prednisone for 5 days ( 3 days before, the day of the procedure and the day after).

-B2 receptor agonist : 0,15 $\mathrm{ml} / \mathrm{kg}$ nebulized salbutamol.

-Antisialogogue premedication: $0.4 \mathrm{mg}$ iv glycopyrrolate.

\section{- Airway Topicalization}

Lidocaine $\mathbf{1 . 5 - 2} \%$ from the supraglottic region down to the bronchial distal tree (max dose: $8 \mathrm{mg} / \mathrm{kg}$ ).
The procedure was completed with no incidents. In the PACU bronchospasm ocurred and was treated successfully with inhaled salbutamol and intravenous steroids. The patient was discharged from hospital after 24 hours.

At 12 months, the mean rate of severe exacerbations was reduced by over $90 \%$.

\section{DISCUSSION}

BT patients require a careful individual evaluation by the medical team to determine suitability.

Topical anesthesia and conscious sedation reduce the response to airway manipulation.

Premedication with corticosteroids is essential to mitigate the peribronchial edema. We preferred glycopyrrolate over atropine because it offers a superior antisialagogue effect and less tachycardia.

\section{LEARNING POINTS}

$\checkmark$ The success of our case is based on an adequate patient selection and preoperative preparation.

$\checkmark$ It required an optimal local anesthesia under conscious sedation to ensure patient comfort and immobility, minimizing stimuli that may induce bronchospamsm.

\section{- Conscious sedation}

Propofol TCl in effect-site control Schnider model $(2 \mathrm{ugr} / \mathrm{ml})+$ Remifentanil $(0.15 \mathrm{ugr} / \mathrm{Kg} / \mathrm{min}$ ) with supplemental oxygen (Fig.3). 